\title{
Open chromatin in pluripotency and reprogramming
}

\author{
Alexandre Gaspar-Maia ${ }^{\# 1,2}$, Adi Alajem ${ }^{\# 3}$, Eran Meshorer ${ }^{3,5}$, and Miguel Ramalho-Santos s $^{1,5}$ \\ ${ }^{1}$ Departments of Ob/Gyn and Pathology, Eli and Edythe Broad Center of Regeneration Medicine \\ and Stem Cell Research, Center for Reproductive Sciences and Diabetes Center, University of \\ California San Francisco, 513 Parnassus Ave, San Francisco, CA, 94143-0525, USA \\ 3 Department of Genetics, Institute of Life Sciences, The Hebrew University of Jerusalem, \\ Jerusalem 91904, Israel
}

\# These authors contributed equally to this work.

\begin{abstract}
Pluripotent stem cells can be derived from embryos or induced from adult cells by reprogramming. They are unique from any other stem cell in that they can give rise to all cell types of the body. Recent findings indicate that a particularly open chromatin state contributes to maintenance of pluripotency. Two emerging principles are that: specific factors maintain a globally open chromatin state that is accessible for transcriptional activation; and other chromatin regulators contribute locally to the silencing of lineage-specific genes until differentiation is triggered. These same principles may apply during reacquisition of an open chromatin state upon reprogramming to pluripotency, and during de-differentiation in cancer.
\end{abstract}

Embryonic stem (ES) cells are the prototypical pluripotent stem cell ${ }^{1-3}$ : they have the capacity to generate differentiated progeny from all three embryonic germ layers (endoderm, mesoderm and ectoderm), as well as the germline ${ }^{4}$. ES cells also have a very high self-renewing capacity and can be expanded essentially indefinitely in culture. In contrast to ES cells, adult stem cells such as neural stem cells ${ }^{5}$ or hematopoietic stem cells 6 have a more restricted differentiation capacity: they usually generate cells of the tissue in which they reside, and are therefore called multipotent.

In recent years there has been an increased interest in pluripotent stem cells because of their promise as models for the study of development and disease in vitro (for examples, see refs $\left.{ }^{7,8}\right)$. However, the derivation of ES cells from early embryos raises technical and ethical limitations to their use in research and the clinic. Pluripotent stem cells can also be derived from both the fetal and the adult germline $e^{9-11}$, and by somatic cell reprogramming. Three major routes for somatic cell reprogramming to pluripotency have been described: nuclear transfer from a somatic cell to an enucleated oocyte, fusion of a somatic cell with an ES cell; and induction of pluripotency in somatic cells by overexpression of key transcription factors (Box 1). All of these reprogramming methods are likely to remain useful and informative in the years ahead. The relative advantages and disadvantages of each reprogramming method have been reviewed elsewhere ${ }^{12}$ and will not be discussed here.

Major excitement has surrounded the process by which pluripotency is induced in somatic cells in the four years since it was described ${ }^{13}$, because of its technical simplicity and broad applicability. Through ectopic expression of genes that are over-represented in ES cells, a

\footnotetext{
${ }^{5}$ Corresponding authors: meshorer@cc.huji.ac.il; mrsantos@diabetes.ucsf.edu.

2 Present address: Mount Sinai School of Medicine, Department of Oncological Sciences, 1425 Madison Ave Rm15-52, New York, NY 10029-1075, USA
} 
set of four transcription factors (Oct4, Sox2, cMyc and Klf4) was shown to reprogramme differentiated mouse cells (both embryonic and adult somatic cells) to induced pluripotent stem (iPS) cells that are very similar to ES cells. The surprising effect of only four factors in inducing such a dramatic change in cell fate initiated a whole new field of research. Importantly, human cells ${ }^{14-17}$ can also be converted into iPS cells using either the same four factors as in mouse or a different combination of factors: OCT4, SOX2, LIN28 and NANOG $^{17}$. Therefore, somatic cell reprogramming, in particular induction towards pluripotency, greatly expands the options for basic research and potential clinical applications of pluripotent stem cells. Understanding the molecular regulation of pluripotency is fundamentally important and will facilitate the safe and efficient application of pluripotent stem cells in the clinic.

The pluripotent stem cell state is under the control of a transcriptional circuitry that includes the reprogramming factors mentioned above (reviewed in ref. ${ }^{12}$ ). Recent studies indicate that this transcriptional programme is implemented in the context of an 'open' chromatin state, and it has been proposed that this state allows transcriptional programmes to switch rapidly upon induction of differentiation ${ }^{18}$. This may be particularly important in pluripotent stem cells, where a broad spectrum of differentiation options need to be available.

Here we discuss how chromatin organization is regulated in pluripotent stem cells. We begin by giving a historical perspective of how the concept of open chromatin has evolved and how it has been associated with pluripotency. We review recent insights into the action of chromatin-remodelling factors that maintain a globally open chromatin state in pluripotent stem cells. Finally, we discuss the implications of these insights for our understanding of cellular reprogramming, and point out recent parallels found between open chromatin and cancer.

\section{Open chromatin and pluripotency \\ Defining open chromatin}

The term chromatin was coined by Walther Flemming in 1882, after developing novel histological staining methods that enabled him to observe a unique fibrous structure in the nucleus. This structure was readily stained and was therefore named chromatin ('stainable material' $)^{19,20}$. Almost 50 years later, in 1928, the distinction between heterochromatin and euchromatin was made by Emil Heitz. He distinguished these two chromatin components based on differential compaction in interphase nuclei ${ }^{21}$ : heterochromatin represented the more densely stained, compacted areas, while euchromatin represented the sparsely stained chromatin.

On the basis of predominantly histological evidence, many stem and progenitor cells have been classically described as having a typical open chromatin conformation mostly devoid of heterochromatin, from neoblast cells in planaria ${ }^{22}$, to hematopoietic stem cells in mammals ${ }^{23}$. In such studies, histological analysis of the nucleus was sufficient to suggest a significant difference in chromatin structure between these progenitor cells and their differentiated progeny.

\section{Open chromatin in pluripotent stem cells}

The idea of open chromatin is supported by more than histological examinations and, in the past several years, the chromatin state of pluripotent stem cells has attracted considerable attention due to its distinct features ${ }^{24}$. Indeed, chromatin in pluripotent stem cells is increasingly being recognized as open when compared with somatic cells, implying that its overall structure is less condensed and that the ratio between euchromatin and heterochromatin is higher than in differentiating cells. 
The first line of evidence came from visualizing chromatin in ES cells using electron microscopy; heterochromatin was prevalent in differentiated cells but much less so in undifferentiated ES cells ${ }^{25}$. Similarly, electron spectroscopic imaging (ESI) demonstrated that the majority of chromatin in ES cells is homogeneously spread and largely devoid of compact heterochromatin blocks, whereas in differentiated cells chromatin appeared heterogeneous with distinct blocks of compaction ${ }^{26}$. Importantly, this pattern of chromatin organization was recently found in vivo: cells in the inner cell mass (ICM) of the mouse blastocyst at day 3.5, the source of ES cells, share the same open chromatin conformation as ES cells ${ }^{27}$. ICM cells have highly dispersed chromatin with a significantly lower number of condensed clusters relative to lineage-committed cells. Analysis of global chromatin compaction using nucleases such as DNase I and micrococcal nuclease (MNase) also indicates that chromatin becomes less accessible and thus less sensitive to nuclease digestion upon differentiation of ES cells to embryoid bodies (EBs) (AA and EM, unpublished observations and Kiyoe Ura, Osaka University, personal communication) or induction of differentiation with retinoic $\operatorname{acid}^{28}$.

The relatively low abundance of heterochromatin also supports the idea of chromatin being in an open conformation. Western blot and immunofluorescence analyses of histone posttranslational modifications (PTMs), such as histone H3 tri-methylated on lysine 9 (H3K9me3), that are enriched in heterochromatin (Box 2) suggest that ES cells have considerably less heterochromatin compared with differentiated cells ${ }^{29}$. Subsequently, ChIP-chip assays for H3K9me2, which forms 'large organized chromatin K9 modifications' (LOCKs) showed that these domains spread considerably during differentiation ${ }^{30}$. Furthermore, ChIP-seq analyses showed that H3K9me3 and H3K27me3 expand from around $4 \%$ genome coverage in ES cells to $12 \%-16 \%$ (respectively) in differentiated cells ${ }^{31}$. On the other hand, histone acetylation, a general mark of open chromatin, has been shown to be increased in undifferentiated human ES cells, particularly at the $\mathrm{H} 3 \mathrm{~K} 9$ residue $^{32}$.

There is also indirect evidence that supports the concept of a preferentially open chromatin state in pluripotent stem cells. In ES cells, fluorescence recovery after photobleaching experiments have indicated that chromatin contains a fraction of loosely bound architectural chromatin proteins, such as core ${ }^{33}$ and linker histones and Heterochromatin Protein 1 $(\mathrm{HP} 1)^{29}$; this is not observed in differentiating cells ${ }^{29,33}$. In addition, the ES cell genome is transcriptionally hyperactive: it transcribes normally silenced repetitive elements as well as coding and non-coding regions, resulting in increased levels of total RNA and mRNA ${ }^{26}$ (Fig. 1). One way to counteract this pervasive transcription in ES cells may be by proteasome-mediated degradation of pre-initiation transcription assemblies that form at specific regulatory genes primed for transcription ${ }^{34}$.

Taken together, these data indicate that chromatin in ES cells is globally decondensed compared with differentiated cells, and that a smaller fraction of the genome in ES cells is organized as repressive heterochromatin.

\section{Control of the chromatin landscape}

Chromatin in ES cells is characterized by a distinct set of features, and insights into the enzymes that modify this structure have provided insights into the control of chromatin state. Genome-wide mapping of core histone PTMs, or histone marks, has been of great use in defining the epigenetic patterns (Box 2) that may regulate pluripotency $30,31,35,36$. In addition, several chromatin-modifying enzymes, such as DNA methyltransferases (DNMTs), histone methyltransferases (HMTs), histone demethylases (HDMs), histone acetyltransferases (HATs), histone deacetylases (HDACs) and chromatin-remodelling 
proteins have recently been shown to have important roles in ES cells, and are described below. An interplay between chromatin regulation and the transcriptional network that governs pluripotency ${ }^{37}$ is also critical and has been reviewed elsewhere ${ }^{38}$.

\section{Chromatin poised for differentiation}

ES cells have a globally open chromatin structure with abundant levels of epigenetic marks that are indicative of active transcription, such as histone $\mathrm{H} 3 \mathrm{~K} 4 \mathrm{me} 3$ and acetylation of histones $\mathrm{H} 3$ and $\mathrm{H} 4^{29,32,39}$. However, there must be countering mechanisms that silence developmental regulatory genes and prevent precocious differentiation. It is thought that these developmental regulators are silenced but poised for activation by the presence of both the activating mark $(\mathrm{H} 3 \mathrm{~K} 4 \mathrm{me} 3)$ and a repressive mark $(\mathrm{H} 3 \mathrm{~K} 27 \mathrm{me} 3)^{35,36,39}$. These so-called 'bivalent' domains, although not strictly specific to ES cells, may lead to the rapid activation of lineage-specific genes through loss of H3K27me3 when differentiation is induced.

The repressive $\mathrm{H} 3 \mathrm{~K} 27$ methylation mark is regulated by the polycomb group of proteins (PcGs). PcG proteins include the polycomb repressive complex 2 (PRC2), which is involved in the addition of the histone mark, and PRC1, which recognizes this mark. Genome-wide analyses of several PcG proteins in both human and mouse ES cells revealed their local enrichment in silenced developmental regulatory genes ${ }^{40,41}$. Moreover, the target genes of PcG proteins tend to be co-occupied by the transcription factors Oct4, Sox 2 and Nanog, which are critical regulators of the pluripotent state. However, PcG proteins are not essential for ES cell self-renewal: in the absence of PcG proteins such as Embryonic ectodermal development (Eed) $)^{40,42}$, Suppressor of zeste 12 homolog (Suz12) $)^{41}$ and Enhancer of zeste homolog $2(E z h 2)^{43}$, ES cells can still be propagated in the undifferentiated state. However, these PcG-deficient ES cells cannot silence several lineage-specific markers and have differentiation defects. PcG proteins are recruited to target DNA by the co-factor Jarid $2^{44}$. Jarid2 also seems to inhibit the enzymatic methyltransferase activity of PRC2, and may therefore regulate both targeting and fine-tuning of PRC2 activity in ES cells and during differentiation ${ }^{44-47}$.

\section{Heterochromatin regulation in ES cells}

Another histone mark commonly associated with gene repression is methylation at $\mathrm{H} 3 \mathrm{~K} 9$, which increases with differentiation of ES cells. One enzyme that is responsible for H3K9 methylation is the histone methyltransferase G9a. Interestingly, G9a is required for the silencing of Oct 4 upon differentiation ${ }^{48}$. G9a binds directly to the promoter of Oct 4 and leads to $\mathrm{H} 3 \mathrm{~K} 9$ methylation, which is followed by recruitment of DNMTs to signal a more definite repressive state. G9a may have a dual role of methylating H3K9 (as a known HMT) and recruiting DNMTs - an example of how several layers of regulation accomplish proper silencing of a particular gene ${ }^{49}$. Therefore, the increase in heterochromatin that occurs upon ES cell differentiation may directly contribute to the silencing of regulators of self-renewal and pluripotency. G9a is also required for the establishment of domains of $\mathrm{H} 3 \mathrm{~K} 9 \mathrm{me} 2$ (LOCKs) in differentiated cells ${ }^{30}$, suggesting a more global role for G9a in differentiationinduced heterochromatinization.

The low level of H3K9 methylation in undifferentiated ES cells is maintained by the histone H3K9 demethylases Jmjd1a and Jmjd2c; these regulate global levels of the repressive marks $\mathrm{H} 3 \mathrm{~K} 9 \mathrm{me} 2$ and $\mathrm{H} 3 \mathrm{~K} 9 \mathrm{me} 3$, respectively, and maintain the ES cell state by directly demethylating $\mathrm{H} 3 \mathrm{~K} 9$ at the promoter regions of core ES cell factors, allowing their expression $^{50}$. Interestingly, the genes encoding Jmjd1a and Jmjd2c are regulated by Oct4, representing an example of a positive feedback-loop that integrates the action of both transcription factors and histone modifiers to maintain the undifferentiated ES cell state. 
A different layer of epigenetic regulation in ES cells is the DNA methylation of CpG islands. DNMTs are responsible for this repressive mark, which is correlated with specific histone marks ${ }^{51}$ : methylated $\mathrm{CpG}$ islands are present mainly at promoter regions of repressed genes, usually correlated with unmethylated H3K4 and with tri-methylated H3K9, and represent around $30 \%$ of genes in ES cells ${ }^{52}$. However, cross-referencing genomic regions with methylation patterns and binding of Oct4, Nanog, Sox 2 and PcG revealed little overla $^{52}$. Moreover, ES cells show a significant enrichment of methylation outside $\mathrm{CpG}$ islands, a feature that seems to be unique to these cells ${ }^{53}$. These observations suggest that DNA methylation may represent a unique epigenetic layer that complements other mechanisms of gene repression and contributes to tight regulation of the transcriptional programmes that are activated upon differentiation.

\section{Chromatin remodeling in ES cells}

The addition or removal of histone marks or DNA methylation is only one way in which the chromatin state can impact the transcriptional programme and thus pluripotency in stem cells. The structure of chromatin itself and the positions of nucleosomes can be altered both globally and at the level of specific genetic loci by chromatin-remodelling proteins that alter the histone-DNA contacts using the energy of ATP hydrolysis ${ }^{54}$. The disruption of the histone-DNA contact itself is poorly understood, but the consequences are that DNA becomes exposed to regulatory proteins, and nucleosomes and the histones become more actively mobile ${ }^{55}$.

Chromatin-remodelling proteins can be divided into four families: SWI/SNF (switching defective/sucrose nonfermenting), CHD (chromodomain helicase DNA-binding), ISWI (imitation switch), and INO80 (inositol requiring 80). Chromatin remodellers usually form a complex that contains a catalytic subunit with a SWI2/SNF2 ATPase domain, a subunit that recognizes chromatin, and additional regulatory subunits that mediate interactions with other proteins and with chromatin itself ${ }^{56}$. At least one member of each of these four families is essential for mouse embryogenesis (Table 1), demonstrating the central role that chromatin remodellers have in development. Recent studies have begun to shed light on the specific roles that chromatin remodellers have in ES cells.

\section{SWI/SNF family}

The SWI/SNF family is composed of two major complexes: BAF (Brg/Brahma-associated factors) and PBAF (polybromo BAF) ${ }^{57}$ (Table 1). There is some heterogeneity in the composition of the BAF and PBAF complexes in different cell types and tissues ${ }^{58}$. ES cells have a specialized subunit composition termed esBAF, which is dynamically regulated during differentiation ${ }^{59}$, and it is not yet clear whether two distinct complexes (esBAF/ esPBAF) exist in ES cells or whether the different subunits combine to form a single esBAF.

BRG1 is the catalytic subunit of the esBAF complex. It is down-regulated upon differentiation, and seems to be gradually replaced by a different catalytic subunit, $\mathrm{BRM}^{59,60}$. Brgl-null mice die at the peri-implantation stage ${ }^{61}$ and knockdown experiments in ES cells resulted in aberrant morphology, decreased proliferation rate, and reduced differentiation capacity ${ }^{26,59,62,63}$. Furthermore, genome-wide ChIP-chip and ChIP-seq experiments revealed enrichment of BRG1 at promoter regions of genes that are also occupied by the pluripotency regulators Oct4, Sox 2 and Nanog 63,64 . Intriguingly, BRG1 inhibition in ES cells leads to up-regulation of both developmental genes and ES cellspecific genes. These results suggest that BRG1 may not only contribute to the repression of developmental genes but may also fine-tune the expression level of ES-cell-specific genes, such as $O c t 4$ and Sox2 ${ }^{63,64}$. 
An additional member of the BAF complex with a role in ES cells is BAF250, which includes two related subunits BAF250A and BAF250B. BAF250A incorporation into the BAF complex is most prominent in undifferentiated ES cells, while BAF250B is mostly incorporated after differentiation ${ }^{59}$. Baf250a-deficient ES cells fail to maintain the expression of stem cell markers, and instead activate genes with known roles in early development and organogenesis ${ }^{65}$. Furthermore, Baf $250 a^{-1-}$ ES cells are prone to differentiation but they appear to have lost the ability to form cells of the mesodermal lineage, in agreement with the absence of detectable mesoderm in early mouse $B a f 250 a^{-/-}$ embryos $^{65}$. Unlike $B a f 250 a^{-1-}$ ES cells, Baf250b ${ }^{-/-}$ES cells give rise to all three germ layers ${ }^{66}$, but disruption of $B a f 250 b$ results in reduced self-renewal ability and accelerated ES cell differentiation ${ }^{66}$.

There are mixed reports as to the role of BAF155 in ES cells. It is highly expressed in ES cells ${ }^{59,28}$ and its reduction leads to aberrant colony morphology $y^{62}$ and decreased Oct 4 expression ${ }^{64}$ in undifferentiated ES cells; however in differentiating ES cells, its loss results in perturbed chromatin condensation and increased Oct 4 expression ${ }^{28}$. Based on these studies, it can be speculated that the stoichiometry of different BAF subunits, and not their actual levels, determines their function, perhaps reconciling these studies.

\section{CHD family}

Four subunits from the CHD family of chromatin-remodelling enzymes - CHD1, CHD3, CHD4 and CHD7 - are implicated in ES cell identity and function, although their mechanisms of action differ. CHD1 and CHD7 have not yet been clearly associated with a known complex (Table 1), but the latter binds multiple subunits of the PBAF complex in neural crest cells derived from human ES cells. In these neural crest cells ${ }^{67}$ and mouse ES cells $^{68}$, CHD7 was enriched, together with $\mathrm{H} 3 \mathrm{~K} 4 \mathrm{me} 1$, at enhancer regions, suggesting that CHD7 may maintain transcriptional competence in both undifferentiated and differentiating ES cells.

CHD1 binds globally to active euchromatin and colocalizes with RNA polymerase II (RNAPII) in ES cells ${ }^{69}$. ES cells in which Chd1 has been depleted by RNA interference accumulate high levels of heterochromatin and, while they can be propagated in the undifferentiated state, they cannot differentiate normally. These results indicate that CHD1 establishes a balance between euchromatin and heterochromatin in ES cells, which may be critical for the maintenance of pluripotency.

CHD3 and CHD4 comprise the catalytic subunit of the NuRD (nucleosome-remodelling) complex (Table 1), which has been implicated in regulation of ES cells. For example, ES cells lacking the NuRD subunit Mbd3 retain their Oct4 expression when induced to differentiate, and show aberrant differentiation potential ${ }^{70,71}$. Mbd3-knockdown ES cells also express trophectodermal markers, which are not usually detected in ES cells. Deletion of another subunit $\mathrm{Hdacl}$ also results in aberrant differentiation of mouse ES cells, leading to spontaneous generation of mesodermal and ectodermal lineages at the expense of endoderm $^{72}$. Importantly, knockout of $\mathrm{Hdacl}$ (but not Hdac2) leads to mouse embryonic lethality ${ }^{73-76}$. NuRD therefore appears to have a dual role in silencing both differentiation genes in ES cells as well as ES-cell-specific genes during differentiation. Finally, NuRD subunits MBD3 and MTA2 interact with the SWI/SNF component BRG1 specifically in ES cells but not in differentiating cells ${ }^{59}$, implying that there may be crosstalk between chromatin-remodelling complexes in pluripotent cells. 
ISWI family

The ISWI family of remodellers can form three distinct complexes - NURF, CHRAC and ACF, of which the NURF (nucleosome remodelling factor) complex seems to have the most prominent role in ES cells. BPTF (bromodomain PHD finger transcription factor), a member of the NURF complex, is required for ES cell differentiation both in vivo and in vitro. Bptfknockout ES cells cannot form teratomas and Bptf knockout EBs exhibit severely defective expression of all three germ layer markers. In line with this, Bptf-knockout mouse embryos are defective in the establishment of the anterior-posterior axis during the earliest stages of development and are embryonically lethal at day $8.5^{77}$ (Table 1).

\section{INO80 family}

The INO80 family members can form three distinct complexes, including INO80 (inositol requiring 80), SRCAP (SNF2-related CREB activator protein) and Tip60-p400 (TATinteracting protein, $60-\mathrm{KD}$ ), but only the last has been shown to be important in ES cells so far. The Tip60-p400 complex facilitates transcription by combining nucleosome remodelling with histone acetylase activity. ES cells depleted in different subunits of the Tip60-p400 complex show strikingly similar phenotypes, including altered colony morphology, decreased proliferation rates, reduced pluripotency and overall reduced viability ${ }^{62}$, which seems to be a phenotype specific to ES cells ${ }^{78}$. Tip60-p400 likely acts to maintain the undifferentiated state of ES cells by binding to H3K4me3 mark, an interaction which is facilitated by Nanog. In addition, Tip60-p400 promotes histone $\mathrm{H} 4$ acetylation at both active and repressed genes ${ }^{62}$, also likely supporting the stem cell state.

Together, these studies highlight the importance of chromatin-remodelling complexes for integrating the transcriptional programme for pluripotency with epigenetic information or for silencing this pluripotency programme upon differentiation. In addition, chromatin remodelling may have a potentially broader role in the global maintenance of the open chromatin state of ES cells.

\section{Maintaining open chromatin in ES cells}

In addition to the effects of enriched active histone marks, open chromatin may also be actively maintained in ES cells by these ATP-dependent chromatin-remodelling enzymes, for example, through the disassembly of nucleosomes and/or the 'unwinding' of higherorder chromatin structures (Box 3). Interestingly, the expression of many of these chromatin-remodelling enzymes is significantly enriched in ES cells, including the esBAF complex and Chd members ${ }^{26}$. It is possible that integrating high levels of active histone marks with the high expression of particular chromatin remodellers globally orchestrates an open chromatin state.

The chromatin remodeller Chd1 may repress formation of heterochromatin in ES cells ${ }^{69}$. However, the mechanisms that orchestrate this opening of chromatin, tilting the balance between euchromatin and heterochromatin towards the former, remain unknown (Fig. 2). Such global 'anti-silencing' mechanisms have been studied in other species, such asbudding and fission yeast, and may help understand the principles that govern this battle between heterochromatin and euchromatin. In yeast, Silent information regulator (Sir) proteins bind preferentially to telomeric regions and promote the formation of heterochromatin. Two redundant mechanisms prevent the spreading of Sir proteins and heterochromatin: the incorporation of the histone variant $\mathrm{H} 2 \mathrm{AZ}$ and the methylation of $\mathrm{H} 3 \mathrm{~K} 4$ mediated by the methyltransferase Set1. Thus, both incorporation of specific histone variants or a modification of canonical histones prevents binding of Sir proteins ${ }^{79}$. Another important anti-silencing mechanism is histone hyperacetylation, which also prevents Sir proteins 
from binding ${ }^{80}$. The local silencing mediated by the Sir family protein Sir3 requires a complex interaction between the histone acetyltransferase Sas2, the histone methyltransferases Dot 1 and Set1, and the histone demethylase Jhd $2^{81}$, which determine the dynamic balance of silencing versus activation by directing a competing addition and removal of methyl groups at H3K4 and H3K79. Therefore, not only can different types of histone modifications (acetylation or methylation) interact to regulate silencing, but there is also a dynamic balance between the opposing actions of histone-modifying enzymes to regulate formation of euchromatin or heterochromatin.

Extrapolating on the telomere studies from yeast, one possible mechanism by which an open chromatin state is maintained in ES cells may be through deposition of specific histone variants. For example, H3.3 has been generally associated with active genes and is less prone to $\mathrm{H} 3 \mathrm{~K} 9$ methylation ${ }^{82,83}$. H3.3 is incorporated in a replication-independent manner by the chaperone HIRA $^{84}$, and typically colocalizes with regions enriched in methylation of $\mathrm{H} 3 \mathrm{~K} 4^{85,86}$. This is thought to be a mechanism by which cells may maintain a transcriptional memory; for example, lineage-specific genes marked by $\mathrm{H} 3.3$ are still expressed after reprogramming in Xenopus laevis ${ }^{87}$. Interestingly, CHD1 is required in the Drosophila melanogaster oocyte for incorporation of $\mathrm{H} 3.3$ into sperm chromatin: Chd1 mutant oocytes cannot incorporate $\mathrm{H} 3.3$ into the male pronucleus, which renders the male genome incapable of contributing to development ${ }^{88}$. These results demonstrate the broad impact that H3.3 incorporation has for male chromatin in Drosophila. The possibility that a similar mechanism, involving H3.3 incorporation, also maintains the global open chromatin state of ES cells warrants future investigation, even because this variant is also present in telomeric regions ${ }^{85}$.

Alternatively, or in addition, other mechanisms may directly protect $\mathrm{H} 3 \mathrm{~K} 4 \mathrm{me} 3$ from demethylation. Binding of chromatin remodellers such as Chd1 directly to H3K4me3 via its chromo domains ${ }^{89}$ may protect against the action of demethylases and selectively cooperate with histone methyltransferases to maintain the H3K4me3 mark. For example, Chd1 binding through its chromodomains interacts with the HMT Ash2 that methylates $\mathrm{H} 3 \mathrm{~K} 4^{90}$. This histone mark prevents the binding of repressive complexes such as the NuRD deacetylation complex ${ }^{91,92}$ and the DNA methyltransferase subunit DNMT3L ${ }^{93}$. The opening of chromatin can also be complemented by histone hyperacetylation, as shown for telomeres in yeast ${ }^{80}$. In fact, the histone acetyltransferase and remodelling complex Tip60-p400 recognizes $\mathrm{H} 3 \mathrm{~K} 4 \mathrm{me} 3$ and depends on this mark to bind its targets ${ }^{62}$.

All these mechanisms may orchestrate a complex, dynamic regulation of open versus compact chromatin in ES cells (Fig. 2). It will therefore be important to determine how epigenetic marks change when regulators of open chromatin such as Chd1 are lost, in a genome-wide manner using ChIP-Seq. Further genetic and biochemical studies, in particular epistatic analyses and dissection of protein-protein interactions, should also help define the relative contribution of these mechanisms to the chromatin state and pluripotency of ES cells.

\section{Lessons from reprogramming to iPS cells}

The process of generating iPS cells reverts somatic cells back to a pluripotent stem cell state very similar to ES cells, and may provide an alternative for dissecting the relationship between open chromatin and pluripotency ${ }^{94}$. While molecular landmarks that arise during the course of reprogramming have been identified, the process remains largely a 'black-box' at the mechanistic level. Upon expression of the reprogramming factors (generally Oct4, Sox2, cMyc and Klf4), alkaline phosphatase (AP) activity and expression of the cell surface marker SSEA1 are early markers of the undifferentiated state, detected as early as 3 and 9 
days, respectively, after the onset of reprogramming in mouse cells. Endogenous expression of Oct 4 and Nanog can be detected only after about 10 days post-induction and the exogenous four factors, generally delivered by viral constructs, need to be expressed during all of that period. However, cells only fully reprogram upon silencing of the viral vectors ${ }^{95}$. The main question that arises is: what are the immediate downstream effects of the reprogramming factors that trigger induction of pluripotency? Oct 4 and Sox 2 are part of an autoregulatory loop that maintains pluripotency in ES cells ${ }^{96}$ and cMyc binds to a separate class of genes not bound by Oct4, Sox 2 or Klf $4{ }^{97}$, in concert with self-renewal regulators such as E2F1 and Zfx. Myc is not essential for reprogramming ${ }^{17,98,99}$, but it facilitates early stages of the process, possibly through its direct action on chromatin ${ }^{100}$, or indirectly, via repression of differentiation genes ${ }^{101}$. The ability to dissect how individual factors contribute to the generation of iPS cells would greatly benefit from methods that allow high efficiency synchronized reprogramming, ideally coupled with analysis at the single cell level, neither of which are as yet possible. Nevertheless, studies so far have already provided insights into chromatin-level regulation of reprogramming.

\section{Chromatin reconfiguration during reprogramming}

A large reconfiguration of the chromatin structure, from DNA methylation to histone modifications and nucleosome spacing, occurs during reprogramming. Such layers of epigenetic regulation are often used as repressive mechanisms in somatic cells to prevent unwanted gene expression from other lineages. How these epigenetic barriers to reprogramming are overcome is a key question. Several lines of evidence support the notion that the process of reprogramming involves rare stochastic epigenetic events. The reprogramming process is slow and gradual, with several intermediate states ${ }^{101-103}$. Reactivation of endogenous ES cell genes such as Oct 4 can occur at very different time points in different iPS cell lines derived from the same clone ${ }^{102}$. Eventually, almost all cells are reprogrammed to pluripotency, albeit with different and often very long latency periods ${ }^{104}$. Inhibition of the p53/p21 pathway and overexpression of Lin 28 accelerate the kinetics of reprogramming by increasing cell division rate, which may facilitate the acquisition of DNA and/or histone modifications. This reinforces the idea that reprogramming is a complex process that may use stochastic events to overcome epigenetic barriers, but the underlying molecular mechanisms remain unknown. Interestingly, some of the same epigenetic barriers may also be overcome in cancer progression (Box 4).

Recent insights have been gained by treating reprogramming cells with agents that affect the chromatin state. In particular, treatment with agents that promote chromatin decondensation, such as the DNA methyltransferase inhibitor 5-aza-cytidine, the HDAC inhibitor valproic acid or a G9a methyltransferase chemical inhibitor, all lead to increased efficiency of iPS cell generation and sometimes can substitute for a particular transcription factor ${ }^{103,105-107}$. It is likely that a key step in the generation of iPS cells is the reopening of the somatic cell chromatin. Consistent with this, in a recent unbiased screen for components of ES cell extracts that facilitate reprogramming, the BAF family components Brg1 and Baf $155^{108}$ could substitute for $\mathrm{cMyc}$. Moreover, they promoted the opening of chromatin during the reprogramming process, through DNA demethylation and increased $\mathrm{H} 3 \mathrm{~K} 4 \mathrm{me} 3$ in the promoter regions of important transcription factors ${ }^{108}$. Suppression of Chd1 also inhibits the generation of iPS cells ${ }^{69}$. Additional evidence comes from other reprogramming assays, such as somatic cell nuclear transfer ${ }^{109}$. Here again, Brg1 is an essential nuclear factor for nuclear reprogramming ${ }^{110}$. Furthermore, treatment with histone deacetylase inhibitors enhances efficiency of development after nuclear transfer ${ }^{111}$. These results suggest that the chromatin remodelers that maintain the ES cell state, including Brg1, Baf155 and Chd1, may re-open chromatin during reprogramming and set the stage for activating the transcriptional network for pluripotency. 


\section{Transcriptional memory}

A final insight into the epigenetic regulation of cell states comes from the recent observation that, although iPS cells are remarkably similar to ES cells, they may have transcriptional differences ${ }^{112,113}$. Mouse iPS cells appear to retain a residual DNA methylation signature of their original somatic cells ${ }^{114}$, and a similar phenomenon is observed in human iPS cells (Ohi et al., submitted). The transcriptional profile of human iPS cells becomes more similar to that of human ES cells after several passages ${ }^{112}$, suggesting that some form of reprogramming happens with continued culturing. The functional significance of these transcriptional differences remains to be fully understood. Interestingly, in frog embryos generated by nuclear transfer of muscle cells, which express the muscle-specific gene myogenic differentiation $1(\mathrm{MyoD})$, expression of this gene is maintained in non-muscle lineages even after several divisions ${ }^{87}$. This transcriptional memory may be mediated through deposition of the histone variant H3.387. This chromatin mark could establish, through an unknown mechanism, a memory of the genes that had been previously transcribed in the somatic cell.

Such epigenetic memory, potentially mediated by DNA methylation or histone variant incorporation, may contribute to differences between iPS cells and ES cells, and suggests that competing epigenetic influences may affect chromatin re-opening during reprogramming. A mechanistic understanding of these epigenetic influences, which is at present lacking, should shed light not only on how iPS cells are generated, but more broadly on cellular transitions that occur during differentiation or transformation.

\section{Conclusions}

Significant new insights have been gained into the regulation of pluripotency and reprogramming at the chromatin level. The emerging picture is that a globally open chromatin state accessible for transcriptional activation is actively maintained in pluripotent stem cells. In this context that is permissive for transcription, there are additional epigenetic mechanisms that promote silencing of lineage-specific genes while leaving them poised for rapid activation. A major gap in our understanding of pluripotency is how the different layers of epigenetic regulation of the chromatin state impact one another and the transcriptional network. Clearly, much effort should now focus on integrating the various levels of epigenetic regulation in pluripotent stem cells, for example, using analyses of genetic epistasis and protein-protein interactions, and understanding how such information may be parsed out during differentiation. New approaches for defining the chromatin landscape are also being established, which will allow for a better understanding of the chromatin structure and its significance for the identity of a particular cell type. For example, the use of DamID in Drosophila has identifed five different types of chromatin (instead of the classic three: euchromatin, heterochromatin and facultative heterochromatin) according to the chromatin proteins that are bound to these domains ${ }^{115}$. They include three types of silencing or repressive chromatin, one bound by HP1, another bound by Polycomb and a third type with no apparent known repressive or active marks, which encompasses more than $50 \%$ of the genome. The euchromatic regions are divided in two domains, one enriched with H3K36me3 and the other one mostly bound by regulatory factors, and include most developmental genes. Studies such as this in mammalian cells will hopefully provide a more comprehensive picture of 'open' and 'closed' chromatin.

In addition, much remains to be learned about the mechanisms that regulate epigenetic reprogramming during generation of iPS cells. We must remember that ES cells and iPS cells are cultured in vitro, and that the molecular mechanisms that underlie their biology evolved for processes in the context of the whole embryo that remain poorly understood and deserve further investigation. Finally, it will be important to assess the significance of the 
intriguing epigenetic similarities observed between pluripotent stem cells and undifferentiated cancer cells (Box 4).

\section{Acknowledgments}

We would like to thank Emily Bernstein and three anonymous reviewers for constructive comments. EM is a Joseph H. and Belle R. Braun Senior Lecturer in Life Sciences and is supported by the Israel Science Foundation (ISF 215/07 and 943/09), the Israel Cancer Research Foundation, the Israel Ministry of Health (6007), the European Union (IRG-206872 and 238176) and an Alon Fellowship. AA is a Safra fellow. Work in the Santos lab is supported by an NIH Director's New Innovator Award, California Institute for Regenerative Medicine and the Helmsley Trust.

\section{Biography}

Alexandre Gaspar-Maia carried out his doctoral research on the regulation of Embryonic Stem cell pluripotency at University of California San Francisco, USA, as part of a PhD program in Biomedicine and Experimental Biology from the University of Coimbra, Portugal. He is now a postdoctoral fellow supported by the Department of Defense, USA in the Department of Oncological Sciences in Mount Sinai School of Medicine, New York, USA. He is now studying chromatin dynamics during cancer progression and stem cell differentiation.

Adi Alajem received a B.A. and an M.Sc. from the Israel Institute of Technology (Technion) and Is currently a Ph.D. student at the lab of Dr Eran Meshorer, in the Hebrew University of Jerusalem, Israel. Her study deals with the role of chromatin proteins in embryonic stem cells and differentiated cells.

Eran Meshorer is a Senior Lecturer at the Hebrew University of Jerusalem, Department of Genetics, where he heads the Stem Cell Chromatin Group. He obtained his Ph.D. from the Hebrew University of Jerusalem, and was a postdoctoral fellow at the National Cancer Institute, NIH. His laboratory seeks to unravel the relationship between chromatin plasticity and pluripotency, focusing on the basic biology of ES cell differentiation and somatic cell reprogramming.

Miguel Ramalho-Santos received a B.Sc. and an M.Sc. from the University of Coimbra, Portugal, and a Ph.D. from Harvard University, USA. He is currently an Assistant Professor of Ob/Gyn and Pathology, and a member of the Eli and Edythe Broad Center for Regeneration Medicine at the University of California, San Francisco, USA. Research in his laboratory focuses on the biology of stem cell pluripotency and reprogramming.

\section{GLOSSARY}

Endoderm

Mesoderm

Ectoderm
The innermost of the three germ layers formed during embryonic development. Prominent examples of endodermal tissues include the epithelia of the gastrointestinal and respiratory tracts, thyroid, liver, pancreas, as well as of the auditory and urinary systems.

The middle of the three germ layers formed during embryonic development. Prominent examples of mesodermal tissues include bone, cartilage, blood, muscle, heart, connective tissue and kidney.

The outermost of the three germ layers formed during embryonic development. Prominent examples of ectodermal tissues include the nervous system, hair, skin, nails and eyes, as well as the 


\section{Heterochromatin}

\section{Euchromatin}

Electron spectroscopic imaging (ESI)

Embryoid bodies (EBs)

Histone

ChIP-chip

ChIP-seq

\section{Heterochromatin protein 1 (HP1)}

Proteasome

CpG island

Helicase domain

Teratoma various derivatives of the neural crest, including bones of the head and peripheral nerves.

Highly compacted chromatin that is transcriptionally inactive. Includes structural regions of the chromosome such as centromeres that lack genes ('constitutive' heterochromatin) and regions in which genes are silenced in a given cell type ('facultative' heterochromatin).

A form of chromatin that is relatively decondensed and often transcriptionally active during interphase.

Energy-filtered transmission electron microscopy in which the image is formed only by electrons transmitted within a certain energy window. It allows direct quantitative imaging of elements within the specimen.

Cellular aggregates produced when ES cells are induced to differentiate in non-adherent conditions, which mimic the early stages of embryogenesis.

A family of small, highly conserved basic proteins that associate with DNA to form a nucleosome. Histones are found in the chromatin of all eukaryotic cells.

Technique in which DNA isolated by ChIP is denatured and hybridized to a tiling array which typically includes probes covering the entire genome. Paired probes indicate that the protein of interest was bound to that particular region of DNA.

Chromatin immunoprecipitation (ChIP) is a method which allows isolation of DNA sequences that are bound to a protein of interest using specific antibodies. ChIP-seq refers to high-throughput sequencing of this isolated DNA, and provides genome-wide information of the DNA binding sites of the protein of interest.

A heterochromatin-binding protein which recognizes and binds to H3K9me3. It includes three isoforms (alpha, beta, gamma) which are encoded by three different genes.

A large multi-subunit protein complex that degrades proteins. Undesired proteins are destined for degradation by the addition of a chain of the small protein ubiquitin, mediated by a family of enzymes called ubiquitin ligases.

A genomic region which contains a relatively high content of CG dinucleotides (the 'p' refers to the phosphodiester bond linking the two bases). $\mathrm{CpG}$ islands are found in many mammalian promoters and unlike scattered $\mathrm{CpGs}$ throughout the genome, which are usually hypermethylated, promoter $\mathrm{CpG}$ islands are normally hypomethylated.

A protein region that can unwind DNA or RNA

A confined tumour originating from pluripotent cells which includes tissues of the three germ layers, endoderm, mesoderm and ectoderm. 
Telomere

\author{
Histone \\ hyperacetylation \\ HIRA
}

Genetic epistasis

DamID
A region of repetitive DNA at the ends of chromosomes, which protects the chromosomes from premature deterioration, rearrangements and chromosome fusion.

A state in which many lysine residues are acetylated on many of the histones present in a given region of chromatin.

A histone chaperone protein which acts to incorporate the histone variant H3.3 in a replication-independent manner.

The relationship or order in which two genes act in a pathway (that is, upstream or downstream, synergistic or antagonistic), which can be studied by analysing single and double mutants.

Method used to analyse binding of proteins to DNA. Genetically modified Drosophila culture cell lines express a fusion protein of interest with a bacterial DNA adenine methyltransferase. Local DNA methyltransferase activity indicates protein binding.

\section{Highlighted references}

1. Evans MJ, Kaufman MH. Establishment in culture of pluripotential cells from mouse embryos. Nature. 1981; 292:154-156. [PubMed: 7242681]

2. Martin G. Isolation of a pluripotent cell line from early mouse embryos cultured in medium conditioned by teratocarcinoma stem cells. Proc Natl Acad Sci USA. 1981; 78:7634-7638. [PubMed: 6950406]

3. Thomson JA, et al. Embryonic stem cell lines derived from human blastocysts. Science. 1998; 282:1145-1147. [PubMed: 9804556]

4. Bradley A, Evans M, Kaufman MH, Robertson E. Formation of germ-line chimaeras from embryoderived teratocarcinoma cell lines. Nature. 1984; 309:255-266. [PubMed: 6717601]

5. Kriegstein A, Alvarez-Buylla A. The glial nature of embryonic and adult neural stem cells. Annu Rev Neurosci. 2009; 32:149-184. [PubMed: 19555289]

6. Dzierzak E. The emergence of definitive hematopoietic stem cells in the mammal. Curr Opin Hematol. 2005; 12:197-202. [PubMed: 15867575]

7. Lee $\mathrm{G}$, et al. Modelling pathogenesis and treatment of familial dysautonomia using patient-specific iPSCs. Nature. 2009; 461:402-406. [PubMed: 19693009]

8. Carvajal-Vergara X, et al. Patient-specific induced pluripotent stem-cell-derived models of LEOPARD syndrome. Nature. 2010; 465:808-812. [PubMed: 20535210]

9. Matsui Y, Zsebo K, Hogan BL. Derivation of pluripotential embryonic stem cells from murine primordial germ cells in culture. Cell. 1992; 70:841-847. [PubMed: 1381289]

10. Resnick JL, Bixler LS, Cheng L, Donovan PJ. Long-term proliferation of mouse primordial germ cells in culture. Nature. 1992; 359:550-551. [PubMed: 1383830]

11. Ko K, et al. Induction of pluripotency in adult unipotent germline stem cells. Cell Stem Cell. 2009; 5:87-96. [PubMed: 19570517]

12. Jaenisch R, Young R. Stem cells, the molecular circuitry of pluripotency and nuclear reprogramming. Cell. 2008; 132:567-582. [PubMed: 18295576]

13. Takahashi K, Yamanaka S. Induction of Pluripotent Stem Cells from Mouse Embryonic and Adult Fibroblast Cultures by Defined Factors. Cell. 2006; 126:663-676. [PubMed: 16904174]

14. Takahashi K, et al. Induction of Pluripotent Stem Cells from Adult Human Fibroblasts by Defined Factors. Cell. 2007; 131:861-872. [PubMed: 18035408]

15. Lowry WE, et al. Generation of human induced pluripotent stem cells from dermal fibroblasts. Proc Natl Acad Sci USA. 2008; 105:2883-2888. [PubMed: 18287077]

16. Park I-H, et al. Reprogramming of human somatic cells to pluripotency with defined factors. Nature. 2008; 451:141-146. [PubMed: 18157115] 
17. Yu J, et al. Induced pluripotent stem cell lines derived from human somatic cells. Science. 2007; 318:1917-1920. [PubMed: 18029452]

18. Meshorer E, Misteli T. Chromatin in pluripotent embryonic stem cells and differentiation. Nat Rev Mol Cell Biol. 2006; 7:540-546. [PubMed: 16723974]

19. Paweletz N. Walther Flemming: pioneer of mitosis research. Nat Rev Mol Cell Biol. 2001; 2:7275. [PubMed: 11413469]

20. Flemming, W.; Zellsubstanz. Kern und Zelltheilung. F.C.W. Vogel; Leipzig: 1882.

21. Heitz E. Das heterochromatin der moose. I Jahrb Wiss Botanik. 1928; 69:762-818.

22. Reddien PW, Sanchez-Alvarado A. Fundamentals of Planarian Regenaration. Annu Rev Cell Dev Biol. 2004; 20:725-757. [PubMed: 15473858]

23. Spangrude GJ, Heimfeld S, Weissman IL. Purification and characterization of mouse hematopoietic stem cells. Science. 1988; 241:58-62. [PubMed: 2898810]

24. Mattout A, Meshorer E. Chromatin plasticity and genome organization in pluripotent embryonic stem cells. Curr Opin Cell Biol. 2010; 22:334-341. [PubMed: 20226651]

25. Park S-H, et al. Ultrastructure of human embryonic stem cells and spontaneous and retinoic acidinduced differentiating cells. Ultrastruct Pathol. 2004; 28:229-38. [PubMed: 15693634]

26. Efroni S, et al. Global transcription in pluripotent embryonic stem cells. Cell Stem Cell. 2008; 2:437-47. [PubMed: 18462694] [Identifies the ES cell genome as transcriptionally hyperactive, and demonstrates - using electron spectroscopic imaging (ESI) - increased heterochromatin in differentiating cells, as well as an abundance of chromatin remodellers in the undifferentiated state.]

27. Ahmed K, et al. Global chromatin architecture reflects pluripotency and lineage commitment in the early mouse embryo. PLoS ONE. 2010; 5:e10531. [PubMed: 20479880] [Describes changes in chromatin structure - using electron spectroscopic imaging (ESI) - in the early embryo, demonstrating that pluripotent epiblast cells in the inner cell mass of the blastocyst have a less condensed chromatin than lineage-committed cells.]

28. Schaniel C, et al. Smarcc1/Baf155 couples self-renewal gene repression with changes in chromatin structure in mouse embryonic stem cells. Stem Cells. 2009; 27:2979-2991. [PubMed: 19785031]

29. Meshorer E, et al. Hyperdynamic plasticity of chromatin proteins in pluripotent embryonic stem cells. Dev Cell. 2006; 10:105-116. [PubMed: 16399082] [Shows increased chromatin plasticity in ES cells and reduced levels of heterochromatin-associated histone modifications, compared with differentiating cells.]

30. Wen B, Wu H, Shinkai Y, Irizarry R, Feinberg A. Large histone H3 lysine 9 dimethylated chromatin blocks distinguish differentiated from embryonic stem cells. Nat Genet. 2009; 41:246250. [PubMed: 19151716]

31. Hawkins RD, et al. Distinct epigenomic landscapes of pluripotent and lineage-committed human cells. Cell Stem Cell. 2010; 6:479-491. [PubMed: 20452322] [Describes changes in the epigenomic landscapes of ES cells compared with differentiated cells and shows the expansion of H3K9me3 and H3K27me3 marks during differentiation.]

32. Krejcí J, et al. Genome-wide reduction in $\mathrm{H} 3 \mathrm{~K} 9$ acetylation during human embryonic stem cell differentiation. J Cell Physiol. 2009; 219:677-687. [PubMed: 19202556]

33. Bhattacharya D, Talwar S, Mazumder A, Shivashankar GV. Spatio-temporal plasticity in chromatin organization in mouse cell differentiation and during Drosophila embryogenesis. Biophys J. 2009; 96:3832-3839. [PubMed: 19413989]

34. Szutorisz H, Georgiou A, Tora L, Dillon N. The proteasome restricts permissive transcription at tissue-specific gene loci in embryonic stem cells. Cell. 2006; 127:1375-1388. [PubMed: 17190601]

35. Bernstein BE, et al. A bivalent chromatin structure marks key developmental genes in embryonic stem cells. Cell. 2006; 125:315-326. [PubMed: 16630819]

36. Pan G, et al. Whole-genome analysis of histone H3 lysine 4 and lysine 27 methylation in human embryonic stem cells. Cell Stem Cell. 2007; 1:299-312. [PubMed: 18371364]

37. Boyer LA, Mathur D, Jaenisch R. Molecular control of pluripotency. Curr Opin Genet Dev. 2006; 16:455-462. [PubMed: 16920351] 
38. Kashyap V, et al. Regulation of stem cell pluripotency and differentiation involves a mutual regulatory circuit of the NANOG, OCT4, and SOX2 pluripotency transcription factors with polycomb repressive complexes and stem cell microRNAs. Stem Cells Dev. 2009; 18:1093-1108. [PubMed: 19480567]

39. Azuara V, et al. Heritable gene silencing in lymphocytes delays chromatid resolution without affecting the timing of DNA replication. Nat Cell Biol. 2003; 5:668-74. [PubMed: 12833066]

40. Boyer LA, et al. Polycomb complexes repress developmental regulators in murine embryonic stem cells. Nature. 2006; 441:349-353. [PubMed: 16625203]

41. Lee TI, et al. Control of developmental regulators by Polycomb in human embryonic stem cells. Cell. 2006; 125:301-313. [PubMed: 16630818]

42. Chamberlain SJ, Yee D, Magnuson T. Polycomb repressive complex 2 is dispensable for maintenance of embryonic stem cell pluripotency. Stem Cells. 2008; 26:1496-1505. [PubMed: 18403752]

43. Shen X, et al. EZH1 mediates methylation on histone H3 lysine 27 and complements EZH2 in maintaining stem cell identity and executing pluripotency. Mol Cell. 2008; 32:491-502. [PubMed: 19026780]

44. Pasini D, et al. JARID2 regulates binding of the Polycomb repressive complex 2 to target genes in ES cells. Nature. 2010; 464:306-310. [PubMed: 20075857]

45. Li G, et al. Jarid2 and PRC2, partners in regulating gene expression. Genes Dev. 2010; 24:368380. [PubMed: 20123894]

46. Peng JC, et al. Jarid2/Jumonji coordinates control of PRC2 enzymatic activity and target gene occupancy in pluripotent cells. Cell. 2009; 139(7):1290-1302. [PubMed: 20064375]

47. Shen $X$, et al. Jumonji modulates polycomb activity and self-renewal versus differentiation of stem cells. Cell. 2009; 139:1303-1314. [PubMed: 20064376]

48. Feldman N, et al. G9a-mediated irreversible epigenetic inactivation of Oct-3/4 during early embryogenesis. Nat Cell Biol. 2006; 8:188-194. [PubMed: 16415856]

49. Epsztejn-Litman S, et al. De novo DNA methylation promoted by G9a prevents reprogramming of embryonically silenced genes. Nat Struct Mol Biol. 2008; 15:1176-1183. [PubMed: 18953337]

50. Loh Y-H, Zhang W, Chen X, George J, Ng H-H. Jmjd1a and Jmjd2c histone H3 Lys 9 demethylases regulate self-renewal in embryonic stem cells. Genes Dev. 2007; 21:2545-2557. [PubMed: 17938240]

51. Meissner A, et al. Genome-scale DNA methylation maps of pluripotent and differentiated cells. Nature. 2008; 454:766-770. [PubMed: 18600261]

52. Fouse SD, et al. Promoter CpG methylation contributes to ES cell gene regulation in parallel with Oct4/Nanog, PcG complex, and histone H3 K4/K27 trimethylation. Cell Stem Cell. 2008; 2:160169. [PubMed: 18371437]

53. Lister R, et al. Human DNA methylomes at base resolution show widespread epigenomic differences. Nature. 2009; 462:315-322. [PubMed: 19829295]

54. de la Serna IL, Ohkawa Y, Imbalzano AN. Chromatin remodelling in mammalian differentiation: lessons from ATP-dependent remodellers. Nat Rev Genet. 2006; 7:461-473. [PubMed: 16708073]

55. Cairns BR. The logic of chromatin architecture and remodelling at promoters. Nature. 2009; 461:193-198. [PubMed: 19741699]

56. Clapier CR, Cairns BR. The biology of chromatin remodeling complexes. Annu Rev Biochem. 2009; 78:273-304. [PubMed: 19355820]

57. Moshkin YM, Mohrmann L, van Ijcken WFJ, Verrijzer CP. Functional differentiation of SWI/SNF remodelers in transcription and cell cycle control. Mol Cell Biol. 2007; 27:651-661. [PubMed: 17101803]

58. Lessard JA, Crabtree GR. Chromatin regulatory mechanisms in pluripotency. Annu Rev Cell Dev Biol. 2010; 26:503-32. [PubMed: 20624054]

59. Ho L, et al. An embryonic stem cell chromatin remodeling complex, esBAF, is essential for embryonic stem cell self-renewal and pluripotency. Proc Natl Acad Sci USA. 2009; 106:51815186. [PubMed: 19279220] [Characterizes a special composition of the SWI/SNF chromatinremodelling complex in ES cells, 'esBAF', and its role in ES cell maintenance and pluripotency.] 
60. Kaeser MD, Aslanian A, Dong M-Q, Yates JR, Emerson BM. BRD7, a novel PBAF-specific SWI/ SNF subunit, is required for target gene activation and repression in embryonic stem cells. J Biol Chem. 2008; 283:32254-32263. [PubMed: 18809673]

61. Bultman S, et al. A Brg1 null mutation in the mouse reveals functional differences among mammalian SWI/SNF complexes. Mol Cell. 2000; 6:1287-1295. [PubMed: 11163203]

62. Fazzio TG, Huff JT, Panning B. An RNAi Screen of Chromatin Proteins Identifies Tip60-p400 as a Regulator of Embryonic Stem Cell Identity. Cell. 2008; 134:162-174. [PubMed: 18614019] [Reports an RNAi screen of chromatin proteins in ES cells and a characterization of the Tip60p400 complex, which is necessary to maintain ES cell identity.]

63. Kidder BL, Palmer S, Knott JG. SWI/SNF-Brg1 regulates self-renewal and occupies core pluripotency-related genes in embryonic stem cells. Stem Cells. 2009; 27:317-328. [PubMed: 19056910]

64. Ho L, et al. An embryonic stem cell chromatin remodeling complex, esBAF, is an essential component of the core pluripotency transcriptional network. Proc Natl Acad Sci USA. 2009; 106:5187-5191. [PubMed: 19279218]

65. Gao X, et al. ES cell pluripotency and germ-layer formation require the SWI/SNF chromatin remodeling component BAF250a. Proc Natl Acad Sci USA. 2008; 105:6656-6661. [PubMed: 18448678]

66. Yan Z, et al. BAF250B-associated SWI/SNF chromatin-remodeling complex is required to maintain undifferentiated mouse embryonic stem cells. Stem Cells. 2008; 26:1155-1165. [PubMed: 18323406]

67. Bajpai R, et al. CHD7 cooperates with PBAF to control multipotent neural crest formation. Nature. 2010; 463:958-962. [PubMed: 20130577]

68. Schnetz MP, et al. Genomic distribution of CHD7 on chromatin tracks H3K4 methylation patterns. Genome Res. 2009; 19:590-601. [PubMed: 19251738]

69. Gaspar-Maia A, et al. Chd1 regulates open chromatin and pluripotency of embryonic stem cells. Nature. 2009; 460:863-868. [PubMed: 19587682] [Identifies a chromatin-remodelling protein that binds to active genes and is required to maintain an open chromatin state and pluripotency in ES cells.]

70. Kaji K, et al. The NuRD component Mbd3 is required for pluripotency of embryonic stem cells. Nat Cell Biol. 2006; 8:285-92. [PubMed: 16462733]

71. Zhu D, Fang J, Li Y, Zhang J. Mbd3, a component of NuRD/Mi-2 complex, helps maintain pluripotency of mouse embryonic stem cells by repressing trophectoderm differentiation. PLoS ONE. 2009; 4:e7684. [PubMed: 19888462]

72. Dovey OM, Foster CT, Cowley SM. Histone deacetylase 1 (HDAC1), but not HDAC2, controls embryonic stem cell differentiation. Proc Natl Acad Sci USA. 2010; 107:8242-8247. [PubMed: 20404188]

73. Guan J-S, et al. HDAC2 negatively regulates memory formation and synaptic plasticity. Nature. 2009; 459:55-60. [PubMed: 19424149]

74. Montgomery RL, et al. Histone deacetylases 1 and 2 redundantly regulate cardiac morphogenesis, growth, and contractility. Genes Dev. 2007; 21:1790-1802. [PubMed: 17639084]

75. Zimmermann S, et al. Reduced body size and decreased intestinal tumor rates in HDAC2-mutant mice. Cancer Res. 2007; 67:9047-9054. [PubMed: 17909008]

76. Trivedi CM, et al. Hdac2 regulates the cardiac hypertrophic response by modulating Gsk3 beta activity. Nat Med. 2007; 13:324-331. [PubMed: 17322895]

77. Landry J, et al. Essential role of chromatin remodeling protein Bptf in early mouse embryos and embryonic stem cells. PLoS Genet. 2008; 4:e1000241. [PubMed: 18974875]

78. Fazzio TG, Panning B. Condensin complexes regulate mitotic progression and interphase chromatin structure in embryonic stem cells. J Cell Biol. 2010; 188:491-503. [PubMed: 20176923]

79. Venkatasubrahmanyam S, Hwang WW, Meneghini MD, Tong AHY, Madhani HD. Genome-wide, as opposed to local, antisilencing is mediated redundantly by the euchromatic factors Set1 and H2A.Z. Proc Natl Acad Sci USA. 2007; 104:16609-16614. [PubMed: 17925448] 
80. Kimura A, Umehara T, Horikoshi M. Chromosomal gradient of histone acetylation established by Sas $2 p$ and Sir $2 p$ functions as a shield against gene silencing. Nat Genet. 2002; 32:370-377. [PubMed: 12410229]

81. Osborne EA, Dudoit S, Rine J. The establishment of gene silencing at single-cell resolution. Nat Genet. 2009; 41:800-806. [PubMed: 19543267]

82. McKittrick E, Gafken PR, Ahmad K, Henikoff S. Histone H3.3 is enriched in covalent modifications associated with active chromatin. Proc Natl Acad Sci USA. 2004; 101:1525-1530. [PubMed: 14732680]

83. Hake SB, et al. Expression patterns and post-translational modifications associated with mammalian histone H3 variants. J Biol Chem. 2006; 281:559-568. [PubMed: 16267050]

84. Tagami H, Ray-Gallet D, Almouzni G, Nakatani Y. Histone H3.1 and H3.3 complexes mediate nucleosome assembly pathways dependent or independent of DNA synthesis. Cell. 2004; 116:5161. [PubMed: 14718166]

85. Goldberg AD, et al. Distinct Factors Control Histone Variant H3.3 Localization at Specific Genomic Regions. Cell. 2010; 140:678-691. [PubMed: 20211137] [Describes the genome-wide incorporation of the histone variant H3.3 in ES cells, and shows that incorporation in gene promoters requires Hira, but incorporation at enhancer elements and telomeres is Hira-independent and requires Atrx and Daxx.]

86. Mito Y, Henikoff JG, Henikoff S. Genome-scale profiling of histone H3.3 replacement patterns. Nat Genet. 2005; 37:1090-1097. [PubMed: 16155569]

87. Ng RK, Gurdon JB. Epigenetic memory of an active gene state depends on histone H3.3 incorporation into chromatin in the absence of transcription. Nat Cell Biol. 2008; 10:102-109. [PubMed: 18066050]

88. Konev AY, et al. CHD1 motor protein is required for deposition of histone variant H3.3 into chromatin in vivo. Science. 2007; 317:1087-1090. [PubMed: 17717186]

89. Sims RJ, et al. Human but not yeast CHD1 binds directly and selectively to histone H3 methylated at lysine 4 via its tandem chromodomains. J Biol Chem. 2005; 280:41789-41792. [PubMed: 16263726]

90. Sims RJ, et al. Recognition of trimethylated histone H3 lysine 4 facilitates the recruitment of transcription postinitiation factors and pre-mRNA splicing. Mol Cell. 2007; 28:665-676. [PubMed: 18042460]

91. Nishioka K, et al. Set9, a novel histone H3 methyltransferase that facilitates transcription by precluding histone tail modifications required for heterochromatin formation. Genes Dev. 2002; 16:479-489. [PubMed: 11850410]

92. Zegerman P, Canas B, Pappin D, Kouzarides T. Histone H3 lysine 4 methylation disrupts binding of nucleosome remodeling and deacetylase (NuRD) repressor complex. J Biol Chem. 2002; 277:11621-11624. [PubMed: 11850414]

93. Ooi SKT, et al. DNMT3L connects unmethylated lysine 4 of histone $\mathrm{H} 3$ to de novo methylation of DNA. Nature. 2007; 448:714-717. [PubMed: 17687327]

94. Ramalho-Santos M. iPS cells: insights into basic biology. Cell. 2009; 138:616-618. [PubMed: 19703387]

95. Brambrink T, et al. Sequential expression of pluripotency markers during direct reprogramming of mouse somatic cells. Cell Stem Cell. 2008; 2:151-159. [PubMed: 18371436]

96. Boyer LA, et al. Core transcriptional regulatory circuitry in human embryonic stem cells. Cell. 2005; 122:947-956. [PubMed: 16153702]

97. Chen X, et al. Integration of external signaling pathways with the core transcriptional network in embryonic stem cells. Cell. 2008; 133:1106-1117. [PubMed: 18555785]

98. Nakagawa M, et al. Generation of induced pluripotent stem cells without Myc from mouse and human fibroblasts. Nat Biotechnol. 2008; 26:101-106. [PubMed: 18059259]

99. Wernig M, et al. A drug-inducible transgenic system for direct reprogramming of multiple somatic cell types. Nat Biotechnol. 2008; 26:916-924. [PubMed: 18594521]

100. Knoepfler PS. Why myc? An unexpected ingredient in the stem cell cocktail. Cell Stem Cell. 2008; 2:18-21. [PubMed: 18371417] 
101. Sridharan R, et al. Role of the murine reprogramming factors in the induction of pluripotency. Cell. 2009; 136:364-377. [PubMed: 19167336]

102. Meissner A, Wernig M, Jaenisch R. Direct reprogramming of genetically unmodified fibroblasts into pluripotent stem cells. Nat Biotechnol. 2007; 25:1177-1181. [PubMed: 17724450]

103. Mikkelsen TS, et al. Dissecting direct reprogramming through integrative genomic analysis. Nature. 2008; 454:49-55. [PubMed: 18509334]

104. Hanna J, et al. Direct cell reprogramming is a stochastic process amenable to acceleration. Nature. 2009; 462:595-601. [PubMed: 19898493] [Shows that all somatic cells are potentially reprogrammable to iPS cells through ectopic expression of the required factors, and that the process is stochastic and that inhibition of the p53/p21 pathway or increased expression of Lin28 or Nanog increases its efficiency.]

105. Huangfu D, et al. Induction of pluripotent stem cells by defined factors is greatly improved by small-molecule compounds. Nat Biotechnol. 2008; 26:795-797. [PubMed: 18568017]

106. Huangfu D, et al. Induction of pluripotent stem cells from primary human fibroblasts with only Oct4 and Sox2. Nat Biotechnol. 2008; 26:1269-1275. [PubMed: 18849973]

107. Shi Y, et al. A combined chemical and genetic approach for the generation of induced pluripotent stem cells. Cell Stem Cell. 2008; 2:525-528. [PubMed: 18522845]

108. Singhal N, et al. Chromatin-Remodeling Components of the BAF Complex Facilitate Reprogramming. Cell. 2010; 141:943-955. [PubMed: 20550931] [Describes a proteomic analysis of the reprogramming factors contained in nuclear fractions of pluripotent stem cells and identifies BAF-complex elements, which are shown to increase efficiency of reprogramming.]

109. Yamanaka S, Blau HM. Nuclear reprogramming to a pluripotent state by three approaches. Nature. 2010; 465:704-712. [PubMed: 20535199]

110. Egli D, Eggan K. Recipient cell nuclear factors are required for reprogramming by nuclear transfer. Development. 2010; 137:1953-1963. [PubMed: 20463036]

111. Kishigami S, et al. Significant improvement of mouse cloning technique by treatment with trichostatin A after somatic nuclear transfer. Biochem Biophys Res Commun. 2006; 340:183189. [PubMed: 16356478]

112. Chin MH, et al. Induced pluripotent stem cells and embryonic stem cells are distinguished by gene expression signatures. Cell Stem Cell. 2009; 5:111-123. [PubMed: 19570518] [Describes some differences in gene and microRNA expression between ES and iPS cells, and analyses changes in early and late passage iPS cells in gene expression and chromatin structure.]

113. Chin MH, Pellegrini M, Plath K, Lowry WE. Molecular analyses of human induced pluripotent stem cells and embryonic stem cells. Cell Stem Cell. 2010; 7:263-269. [PubMed: 20682452]

114. Kim K, et al. Epigenetic memory in induced pluripotent stem cells. Nature. 2010; 467:285-290. [PubMed: 20644535] [Defines DNA methylation differences in iPS cells depending on their somatic cell of origin, which can be reset by using serial reprogramming or through the use of chromatin-modifying drugs.]

115. Filion GJ, et al. Systematic protein location mapping reveals five principal chromatin types in Drosophila cells. Cell. 2010; 143:212-224. [PubMed: 20888037] [Describes the identification of five major chromatin domains in Drosophila melanogaster cells, each defined by the binding of different combinations of chromatin proteins. Also reports a repressive domain that covers about half of the genome and lacks classic heterochromatin markers.]

116. Bjerkvig R, Tysnes BB, Aboody KS, Najbauer J, Terzis AJA. Opinion: the origin of the cancer stem cell: current controversies and new insights. Nat Rev Cancer. 2005; 5:899-904. [PubMed: 16327766]

117. Ruiz i Altaba A, Sánchez P, Dahmane N. Gli and hedgehog in cancer: tumours, embryos and stem cells. Nat Rev Cancer. 2002; 2:361-372. [PubMed: 12044012]

118. Reya T, Morrison SJ, Clarke MF, Weissman IL. Stem cells, cancer, and cancer stem cells. Nature. 2001; 414:105-111. [PubMed: 11689955]

119. Ben-Porath I, et al. An embryonic stem cell-like gene expression signature in poorly differentiated aggressive human tumors. Nat Genet. 2008; 40:499-507. [PubMed: 18443585]

120. Komashko VM, et al. Using ChIP-chip technology to reveal common principles of transcriptional repression in normal and cancer cells. Genome Res. 2008; 18:521-532. [PubMed: 18347325] 
121. Widschwendter M, et al. Epigenetic stem cell signature in cancer. Nat Genet. 2007; 39:157-158. [PubMed: 17200673]

122. Ohm JE, et al. A stem cell-like chromatin pattern may predispose tumor suppressor genes to DNA hypermethylation and heritable silencing. Nat Genet. 2007; 39:237-42. [PubMed: 17211412]

123. Wong DJ, et al. Module map of stem cell genes guides creation of epithelial cancer stem cells. Cell Stem Cell. 2008; 2:333-344. [PubMed: 18397753]

124. Knoepfler PS, et al. Myc influences global chromatin structure. EMBO J. 2006; 25:2723-34. [PubMed: 16724113]

125. Cotterman R, et al. N-Myc regulates a widespread euchromatic program in the human genome partially independent of its role as a classical transcription factor. Cancer Res. 2008; 68:96549662. [PubMed: 19047142]

126. Frye M, Fisher AG, Watt FM. Epidermal stem cells are defined by global histone modifications that are altered by Myc-induced differentiation. PLoS ONE. 2007; 2:e763. [PubMed: 17712411]

127. Kim J, et al. A Myc Network Accounts for Similarities between Embryonic Stem and Cancer Cell Transcription Programs. Cell. 2010; 143:313-324. [PubMed: 20946988]

128. Dialynas GK, Vitalini MW, Wallrath LL. Linking Heterochromatin Protein 1 (HP1) to cancer progression. Mutat Res. 2008; 647:13-20. [PubMed: 18926834]

129. Kirschmann DA, et al. Down-regulation of HP1Hsalpha expression is associated with the metastatic phenotype in breast cancer. Cancer Res. 2000; 60:3359-3363. [PubMed: 10910038]

130. Tiwari VK, et al. PcG proteins, DNA methylation, and gene repression by chromatin looping. PLoS Biol. 2008; 6:2911-2927. [PubMed: 19053175]

131. Daley GQ. Common themes of dedifferentiation in somatic cell reprogramming and cancer. Cold Spring Harb Symp Quant Biol. 2008; 73:171-174. [PubMed: 19150965]

132. Kim JK, et al. Srg3, a mouse homolog of yeast SWI3, is essential for early embryogenesis and involved in brain development. Mol Cell Biol. 2001; 21:7787-7795. [PubMed: 11604513]

133. Klochendler-Yeivin A, et al. The murine SNF5/INI1 chromatin remodeling factor is essential for embryonic development and tumor suppression. EMBO Rep. 2000; 1:500-506. [PubMed: 11263494]

134. Shawlot W, Deng JM, Fohn LE, Behringer RR. Restricted beta-galactosidase expression of a hygromycin-lacZ gene targeted to the beta-actin locus and embryonic lethality of beta-actin mutant mice. Transgenic Res. 1998; 7:95-103. [PubMed: 9608737]

135. Marfella CGA, et al. Mutation of the SNF2 family member Chd 2 affects mouse development and survival. J Cell Physiol. 2006; 209:162-171. [PubMed: 16810678]

136. Hurd EA, et al. Loss of Chd7 function in gene-trapped reporter mice is embryonic lethal and associated with severe defects in multiple developing tissues. Mamm Genome. 2007; 18:94-104. [PubMed: 17334657]

137. Nishiyama M, et al. CHD8 suppresses p53-mediated apoptosis through histone H1 recruitment during early embryogenesis. Nat Cell Biol. 2009; 11:172-182. [PubMed: 19151705]

138. Marino S, Nusse R. Mutants in the mouse NuRD/Mi2 component P66alpha are embryonic lethal. PLoS ONE. 2007; 2:e519. [PubMed: 17565372]

139. Hu Y, et al. Homozygous disruption of the Tip60 gene causes early embryonic lethality. Dev Dyn. 2009; 238:2912-2921. [PubMed: 19842187]

140. Tominaga K, et al. MRG15 regulates embryonic development and cell proliferation. Mol Cell Biol. 2005; 25:2924-2937. [PubMed: 15798182]

141. Herceg Z, et al. Disruption of Trrap causes early embryonic lethality and defects in cell cycle progression. Nat Genet. 2001; 29:206-211. [PubMed: 11544477] 


\section{Box 1 Pluripotent stem cells can be derived from several sources}

There are three sources of pluripotent stem cells in vivo. Embryonic stem (ES) cells are derived from the inner cell mass of the blastocyst, prior to embryo implantation ${ }^{1-3}$. Embryonic germ (EG) cells are derived from primordial germ cells (PGCs) during midgestation (embryonic days 8.5-12.5 in the mouse) ) $^{9,10}$ and germline-derived pluripotent stem (gPS) cells are derived from spermatogonial stem cells of neonatal and adult testis ${ }^{11}$.

In addition three major routes for somatic cell reprogramming to pluripotency have been described $^{12}$ : fusion between a somatic cell and an ES cell giving rise to reprogrammed hybrid cells; the generation of nuclear transfer embryonic stem (NT-ES) cells, produced by reprogramming of a somatic nucleus by an enucleated oocyte, which is then cultured to the blastocyst stage to allow derivation of ES cells; and the production of induced pluripotent stem cells (iPS), derived by overexpression in somatic cells of reprogramming transcription factors, most commonly the POU domain class 5 transcription factor 1 (Pou5f1, also known as Oct4), the Sry-box containing gene 2 (Sox2), the Myelocytomatosis oncogene (cMyc) and the Kruppel-like factor 4 (Klf4) ${ }^{13}$.

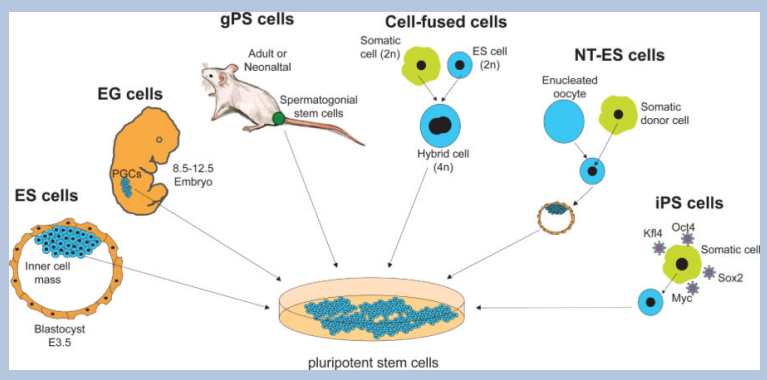




\section{Box 2 Chromatin and epigenetic patterns}

Chromatin is a complex assembly of DNA, histone proteins and other non-histone protein components. Histone proteins form chromatin building blocks, the nucleosomes, around which DNA is wrapped. Each nucleosome consists of an octamer of the canonical core histones $\mathrm{H} 2 \mathrm{~A}, \mathrm{H} 2 \mathrm{~B}, \mathrm{H} 3$ and $\mathrm{H} 4$ and, between two nucleosomes, the histone $\mathrm{H} 1$ acts as a linker. Alterations to the chromatin structure that do not affect the genomic sequence are defined as epigenetic modifications. These epigenetic patterns include methylation of DNA, post-translational modifications (PTMs) of histones (also called histone marks) and histone variants that are incorporated into nucleosomes.

The N-terminal tails of histones are subject to various PTMs, including acetylation, methylation, phosphorylation, ubiquitylation, poly-ADP ribosylation and proline isomeration, with either activating or inhibiting effects on transcription. The most commonly studied are: methylation, in which histone methyltransferases (HMTs) add a methyl group and histone demethylases (HDMs) remove this group; and acetylation, In which the addition and removal of an acetyl group is regulated by histone acetyltransferases and histone deacetylases (HDACs), respectively. Typically, the trimethylation of lysine 4 in $\mathrm{H} 3$ (H3K4me3), together with histone acetylation, signal binding of RNA polymerase II and transcriptional activation. Tri-methylation of lysine 27 in H3 (H3K27me3) and tri-methylation of lysine 9 in H3 (H3K9me3) signal a repressive transcriptional state, although through recruitment of distinct silencing factors. Chromatin remodelling complexes also often include regulators of PTMs and may mediate incorporation of histone variants (such as $\mathrm{H} 3.3$ and $\mathrm{H} 2 \mathrm{AZ}$ or macroH2A), which can either be associated with inactive or active chromatin ${ }^{58}$.

Modification of the DNA itself is also important. Cytosine DNA methylation on cytosine and guanine dinucleotides (CpG islands) is mediated by DNA methyltransferases (DNMTs) and is usually repressive. DNA methylation is typically a more stable and inheritable epigenetic pattern that can persist for several cell generations. However, DNA methylation can be lost passively by a lack of methylation after replication, and there also appear to be factors that can actively de-methylate DNA ${ }^{58}$. 


\section{Box 3 The actions of chromatin-remodelling factors}

Chromatin remodellers are ATP-dependent machines that act to alter the local structure of chromatin by repositioning (or 'sliding'), ejecting or incorporating nucleosomes. During DNA replication, for example, a group of chromatin remodellers act to insert nucleosomes into the newly forming chromatin fibre (bottom left in the figure), but other groups of remodellers are active throughout the cell cycle to modify the local structure of chromatin, thereby regulating gene expression. For example, chromatin-remodelling factors such as SWI/SNF and CHD family proteins can trigger ejection of a nucleosome (top left). Others such as ISWI family proteins can repositioning or 'slide' a nucleosome (top right). The INO80 family proteins exchange histone dimers (bottom right), which can introduce histone variants or modified histones, and have a local impact on chromatin activity $^{56}$.

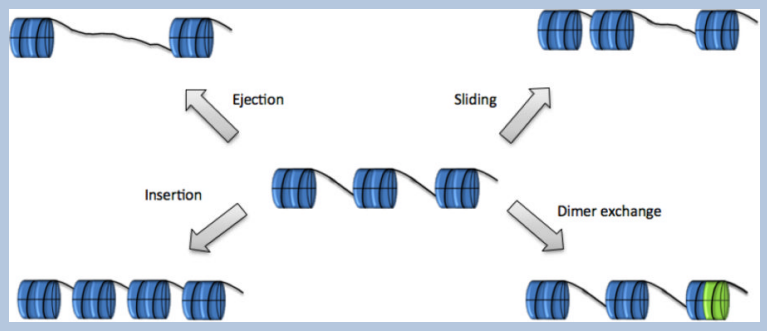




\section{Box 4 Open chromatin and the undifferentiated state in cancer cells}

The acquired ability of cancer cells to divide perpetually and at the same time to support tumor growth, metastasis and invasiveness, bears resemblance to stem cell biology ${ }^{116}$. It is thought that this acquired immortality is obtained through the activation of stem-cellspecific pathways that are essential for self-renewal, such as Wnt, Sonic hedgehog (Shh) or Notch pathways ${ }^{117,118}$. There is also a correlation between the transcriptome of stem cells and highly undifferentiated cancer cells from tumours with higher proliferation rates and poorer prognosis ${ }^{119-123}$. For example, Myc can reactivate an ES cell-like programme in normal and cancer cells ${ }^{123}$. However, Myc has several functions, and the mechanism by which Myc activates this ES cell-like programme could be independent of its canonical transcription factor activity ${ }^{124}$. In particular, Myc regulates large domains of euchromatin, possibly by inducing histone hyperacetylation ${ }^{125,126}$. It is therefore possible that there are commonalities between undifferentiated cancer cells and ES cells that include a shared transcriptional programme linked with reorganization of the chromatin to include euchromatic histone marks ${ }^{127}$.

Some aspects of higher order chromatin conformation may have similarities between ES cells and certain undifferentiated types of cancer. For example, loss of heterochromatin markers such as HP1-alpha ${ }^{128,129}$ and $\mathrm{H} 3 \mathrm{~K} 9 \mathrm{me}^{30}$ have been observed in metastatic breast cancer and lymphoid cancer cell lines, respectively. In addition, many genes marked with bivalent domains in ES cells, including tumor suppressors and prodifferentiation factors, further acquire H3K9 methylation in embryonic carcinoma cells and DNA methylation in adult cancer cells ${ }^{120}$. These additional repressive marks may contribute to a higher order chromatin organization and permanent silencing of tumour suppressors and pro-differentiation factors in cancer cells ${ }^{130}$. Furthermore, the process of inducing pluripotency has similarities to cellular transformation and is facilitated by the activation of oncogenes such as cMyc and the inhibition of tumor suppressors like p53 (for a review, see refs ${ }^{94,131}$ ). It will therefore be of interest to explore potential parallels between the regulation of the chromatin state in pluripotent stem cells and cancer cells. 


\section{Online summary}

Pluripotent stem cells, such as embryonic stem cells, maintain the capacity to differentiate into all cell types of the body through a complex regulatory mechanism that involves a particular chromatin landscape.

Pluripotent stem cells have been shown by a variety of approaches to have an open chromatin state, with reduced levels of heterochromatin, both in vitro and in vivo. This open chromatin state is thought to be important for the maintenance of pluripotency.

Open chromatin may be regulated by several chromatin regulators that are abundant in embryonic stem cells. These factors appear to actively prevent heterochromatin from expanding in the undifferentiated state.

In the context of a globally open chromatin, other chromatin regulators contribute locally to the silencing of lineage-specific genes until differentiation is triggered, keeping pluripotent stem cells in a 'poised' undifferentiated state.

Reprogramming of somatic cells to pluripotent stem cells requires re-opening of chromatin in a process that probably involves some of the same factors that maintain open chromatin. Chromatin re-opening during reprogramming may not always be complete, and thus leaves an epigenetic memory of the original cell type.

The overcoming of epigenetic barriers during somatic cell reprogramming to pluripotency appears to have molecular parallels with cellular transformation in cancer. 

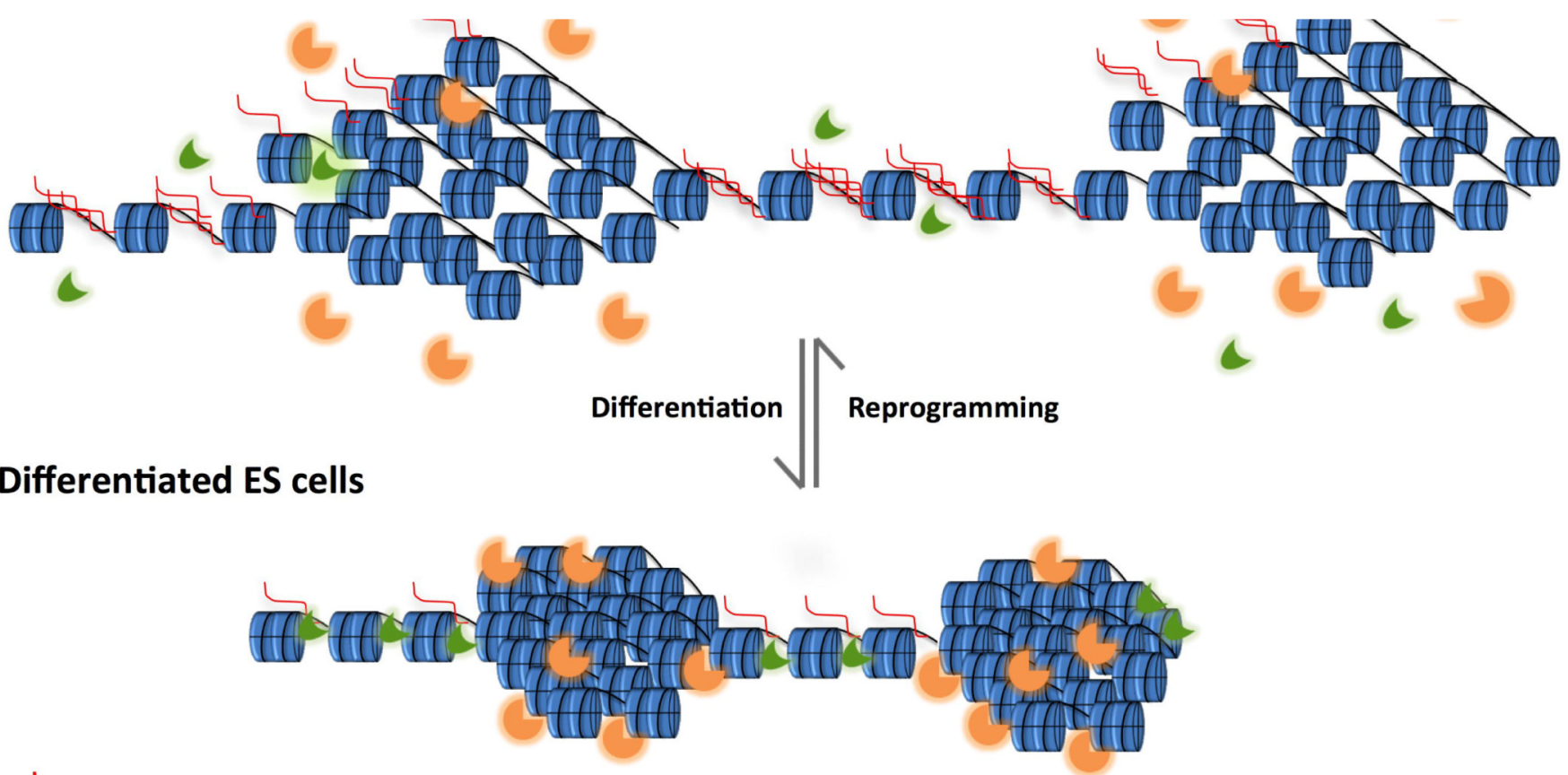

RNA transcripts

HP1

H1

Figure 1. Chromatin in pluripotent stem cells vs. differentiated cells

The structure of chromatin differs between undifferentiated ES cells (top) and differentiated cells (bottom) in several ways. Chromatin structure becomes more condensed upon differentiation and more open upon reprogramming. In ES cells, chromatin is globally decondensed; there are fewer heterochromatin foci and they are larger and more dispersed compared with those of differentiated cells. Architectural chromatin proteins, represented here by the histone H1 (green) and HP1 (orange), are loosely bound to chromatin in ES cells and are bound more tightly to chromatin in differentiated cells. In ES cells, chromatin, including heterochromatin, is transcriptionally hyperactive, shown here by high levels of RNA transcripts (red). 


\section{Euchromatin ? Heterochromatin}

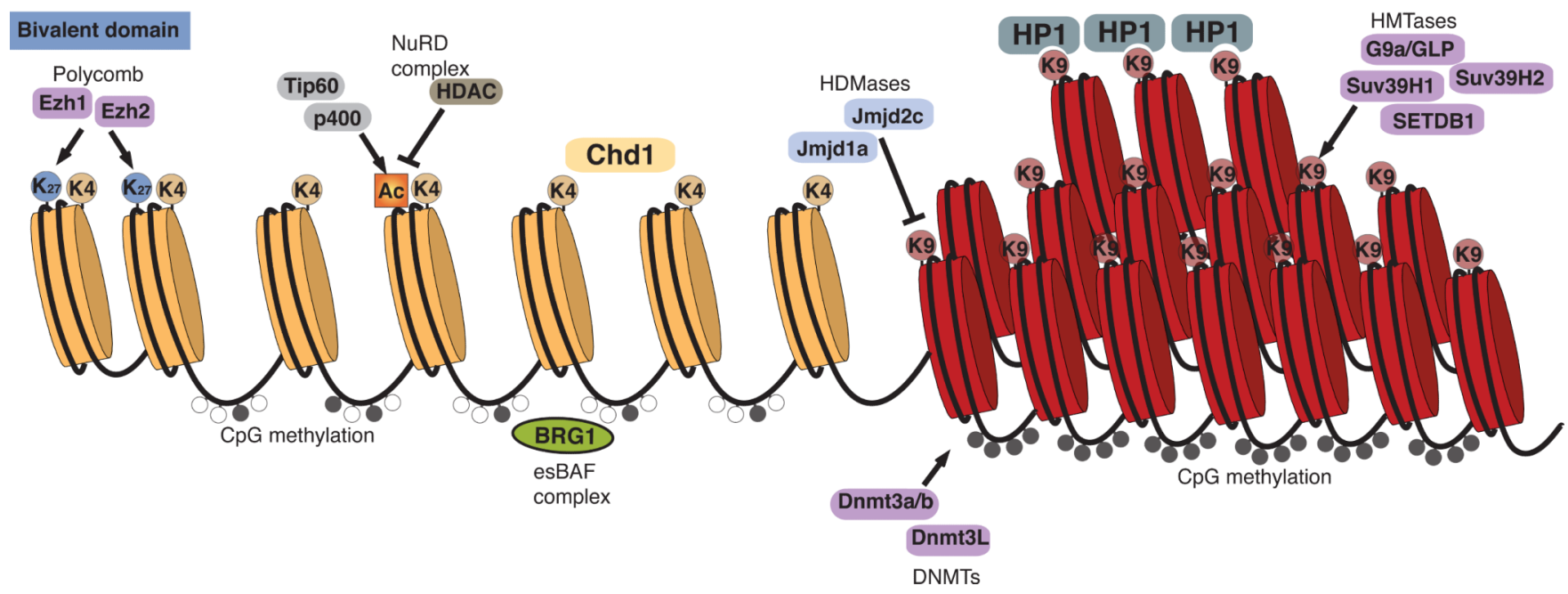

Figure 2. The balance between euchromatin and heterochromatin in ES cells

Several epigenetic regulators orchestrate the open chromatin state of ES cells and set the stage for the transcriptional network. Relevant epigenetic marks include histone modifications and incorporation of different core histones (yellow and red cylinders) that alter access and efficiency of the transcriptional machinery. The main histone marks, the active $\mathrm{H} 3 \mathrm{~K} 4 \mathrm{me} 3$ and the repressive $\mathrm{H} 3 \mathrm{~K} 9 \mathrm{me} 3$ and $\mathrm{H} 3 \mathrm{~K} 27 \mathrm{me} 3$ (represented by the circles $\mathrm{K} 4, \mathrm{~K} 9$ and K27) are positively regulated by specific HMTs and negatively regulated by the respective HDMs. Active (K4) and repressive (K27) marks can be present in the promoter regions of developmental genes to prevent their expression while allowing rapid activation (bivalent domains). Histone acetylation also marks active chromatin, and the acetyl group (the orange square Ac) can be added through complexes like Tip60-p400 and removed by HDACs, which can be part of repressive complexes like NuRD.. DNA (black line) methylation is typically present in $\mathrm{CpG}$ islands in promoter regions and heterochromatin (marked by H3K9me3 and HP1). DNA can be hypermethylated (dark grey circles), as the result of DNMTs, but in euchromatic regions DNA is generally unmethylated (white circles). Chromatin remodeling proteins such as CHD1 and BRG1 in the EsBAF complex may regulate the open chromatin state, possibly by contributing to defining the boundaries between euchromatin and heterochromatin. 
Table 1

Chromatin remodelers in ES cells.

\begin{tabular}{|c|c|c|c|c|c|c|}
\hline \multirow[t]{2}{*}{ Family } & \multirow[t]{2}{*}{ Complex } & \multirow{2}{*}{ Subunits / Protein } & \multicolumn{3}{|c|}{ Effect on ES Cells } & \multirow{2}{*}{ Embryonic lethality } \\
\hline & & & M & $\mathbf{P}$ & D & \\
\hline \multirow{18}{*}{ SWI/SNF } & \multirow{9}{*}{ BAF } & BRG1 & YES $(59,62,63)$ & YES $(59,26)$ & YES $(59,26,63)$ & (61) \\
\hline & & BAF250A & YES $(65,62)$ & YES (65) & YES(65) & (65) \\
\hline & & BAF250B & NO (66) & YES (66) & YES(66) & N/A \\
\hline & & BAF155 & YES (62) & YES (59) & N/A & (132) \\
\hline & & BAF60A & \multicolumn{3}{|c|}{ N/A } & N/A \\
\hline & & BAF57 & \multicolumn{3}{|c|}{ N/A } & N/A \\
\hline & & BAF53A & \multicolumn{3}{|c|}{ N/A } & N/A \\
\hline & & BAF47 & \multicolumn{3}{|c|}{ N/A } & (133) \\
\hline & & $\beta$-ACTIN & \multicolumn{3}{|c|}{ N/A } & (134) \\
\hline & \multirow{9}{*}{ PBAF } & BRG1 & YES $(59,62,63)$ & YES $(59,26)$ & YES $(59,26,63)$ & (61) \\
\hline & & BAF200 & \multicolumn{3}{|c|}{ N/A } & N/A \\
\hline & & BAF180 & \multicolumn{3}{|c|}{ N/A } & N/A \\
\hline & & BAF155 & YES (62) & YES (59) & N/A & (132) \\
\hline & & BAF60A & \multicolumn{3}{|c|}{ N/A } & N/A \\
\hline & & BAF57 & \multicolumn{3}{|c|}{ N/A } & N/A \\
\hline & & BAF53A & \multicolumn{3}{|c|}{ N/A } & N/A \\
\hline & & BAF47 & \multicolumn{3}{|c|}{ N/A } & (133) \\
\hline & & $\beta$-ACTIN & \multicolumn{3}{|c|}{ N/A } & (134) \\
\hline \multirow{12}{*}{ CHD } & N/A & CHD1 & NO (69) & YES (69) & YES (69) & N/A \\
\hline & N/A & CHD2 & & N/A & & (135) \\
\hline & N/A & CHD7 & & N/A & & (136) \\
\hline & N/A & CHD8 & & N/A & & (137) \\
\hline & \multirow{8}{*}{ NuRD } & CHD3,4 & \multicolumn{3}{|c|}{ N/A } & N/A \\
\hline & & GATAD2A & \multicolumn{3}{|c|}{ N/A } & (138) \\
\hline & & GATAD2B & \multicolumn{3}{|c|}{ N/A } & N/A \\
\hline & & HDAC1 & N/A & N/A & YES (72) & (74) \\
\hline & & HDAC2 & \multicolumn{3}{|c|}{$\mathrm{NO}(72)$} & (76) \\
\hline & & MBD3 & YES (71) & YES $(70,71)$ & YES $(70,71)$ & N/A \\
\hline & & MTA1,2,3 & \multicolumn{3}{|c|}{ N/A } & N/A \\
\hline & & RBBP4/7 & & N/A & & N/A \\
\hline & & SNF2L & & N/A & & N/A \\
\hline ISWI & NURF & BPTF & N/A & YES (77) & YES (77) & (77) \\
\hline & & RBBP4/7 & & N/A & & N/A \\
\hline & & EP400 (p400) & YES (62) & YES (62) & YES (62) & N/A \\
\hline INO80 & TIP60 & BAF53A & & N/A & & N/A \\
\hline & & BRD8 & & N/A & & N/A \\
\hline
\end{tabular}




\begin{tabular}{|c|c|c|c|c|c|c|}
\hline \multirow[t]{2}{*}{ Family } & \multirow[t]{2}{*}{ Complex } & \multirow{2}{*}{ Subunits / Protein } & \multicolumn{3}{|c|}{ Effect on ES Cells } & \multirow{2}{*}{ Embryonic lethalit } \\
\hline & & & $\bar{M}$ & $\mathbf{P}$ & D & \\
\hline & & DMAP1 & YES (62) & YES (62) & YES (62) & N/A \\
\hline & & EPC1, EPC-like & \multicolumn{3}{|c|}{ N/A } & N/A \\
\hline & & HTATIP (TIP60) & YES (62) & YES (62) & YES (62) & (139) \\
\hline & & MEAF6 & \multicolumn{3}{|c|}{ N/A } & N/A \\
\hline & & MRGBP & \multicolumn{3}{|c|}{ N/A } & N/A \\
\hline & & MRGX & \multicolumn{3}{|c|}{ N/A } & N/A \\
\hline & & MRG15 & \multicolumn{3}{|c|}{ N/A } & (140) \\
\hline & & RUVBL1,2 & YES (62) & YES (62) & N/A & N/A \\
\hline & & TRRAP & YES (62) & YES (62) & N/A & (141) \\
\hline & & YEATS4 & YES (62) & YES (62) & N/A & N/A \\
\hline & & VPS72 & \multicolumn{3}{|c|}{ N/A } & N/A \\
\hline & & $\beta$-ACTIN & \multicolumn{3}{|c|}{ N/A } & (134) \\
\hline
\end{tabular}

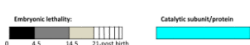

M - Morphology defects; P - Proliferation defects; D - Differentiation defects; N/A - Not Available

A gray-scale color-code depicts the stage of embryonic lethality; Turquoise denotes the catalytically active subunit. M - Morphology defects; P Proliferation defects; D - Differentiation defects; N/A - Data Not Available 